ISSN: 2526-7884

Editor: Prof. Dr. Marconi Freitas da Costa Email da revista: cbr@ufpe.br
Avaliação: Double blind review

Recebido: 25 de fevereiro de 2019

Aceito: 14 de maio de 2019

\title{
FATORES QUE INFLUENCIAM NO CONSUMO DE CARNE OVINA
}

\author{
Luthieli Lopes dos Santos \\ Gustavo da Rosa Borges
}

Luthieli Lopes dos Santos é Acadêmica da Pós-Graduação em Agronegócios da

Universidade Federal do Pampa -

UNIPAMPA. E-mail:

luthieli_ls_@hotmail.com.

Gustavo da Rosa Borges é Professor do

Programa de Pós-Graduação em

Administração da Universidade Federal do

Pampa - UNIPAMPA. E-mail:

gustavodarosaborges@gmail.com.

Os autores agradecem aos avaliadores pelos comentários para melhoria do artigo.

\begin{abstract}
Resumo
A presente pesquisa se propôs a analisar quais as variáveis são mais relevantes para os consumidores de carne ovina no município de Dom Pedrito - RS, tendo como objetivo, analisar suas percepções, verificar quais os fatores possuem maior relevância para o consumo da carne, e qual a relação das variáveis com a frequência de consumo. A metodologia utilizada foi à aplicação de um questionário Survey, para coletar dados primários em pontos estratégicos de venda de carne ovina e análise através de estatística descritiva. Obteve-se como resultado atributos intrínsecos como sabor, textura e maciez, e atributos extrínsecos como preço. Além disso, o preço foi a variável responsável por nortear a frequência de consumo. Por fim, estudos que visem o mercado consumidor são de fundamental importância para a cadeia produtiva, pois através das percepções dos consumidores, pode-se oferecer um produto que atenda às necessidades e demanda dos consumidores.

Palavras-Chave: Comportamento do Consumidor, Mercado, Carne Ovina, Consumo, Ovinocultura.
\end{abstract}

Esta obra está licenciada com uma Licença Creative Commons Atribuição 4.0 Internacional.

\section{INTRODUÇÃO}

A ovinocultura é uma atividade que está presente na humanidade desde os primórdios da história, onde se criavam animais através de pastoreios, e no Brasil foram introduzidos durante o século XVI e nesse período explorouse a produção de lã da espécie (Paiva, 2005). A atividade está presente em praticamente todos os continentes, sendo que a ampla difusão da espécie se deve principalmente a seu poder de adaptação a diferentes climas, relevos e vegetações. A criação ovina está destinada tanto à exploração econômica como à subsistência das famílias de zonas rurais (Viana, 2008). 
Ao final da década de 1980 ocorreu a crise da lã, a qual foi causada pelo aumento dos estoques de lã da Austrália, da comercialização de tecidos sintéticos e de uma série de crises e colapsos mundiais que ocorreram nesse período (Nocchi, 2001). Como consequência desses acontecimentos, o número de ovinos criados no Rio Grande do Sul diminuiu bruscamente, afetando consideravelmente a produção devido a diminuição da demanda pela fibra, levando a alguns produtores a mudarem de atividade ou até mesmo falirem (Viana, 2008).

A cadeia da carne ovina é considerada como desestruturada e com baixa coordenação, que ocorre devido à falta de comunicação entre os elos que compõem o complexo, e ainda, pela falta de padronização e a abertura para caminhos alternativos para a comercialização (Canozzi et al., 2013). Isso se dá, pela falta de utilização de práticas e ferramentas estratégicas para a coordenação, com o intuito de melhorar a segurança alimentar, a qualidade e o padrão dos produtos, para que se possa ampliar o mercado consumidor e atender as exigências que os consumidores impõem para que haja o fortalecimento do complexo (Saab et al., 2009; Bankut et al., 2013).

O comportamento do consumidor pode ser definido como a ciência que estuda como os indivíduos, grupos e organizações selecionam, compram, usam e descartam bens e serviços, ideias ou experiências que satisfazem suas necessidades e desejos (Kotler, \& Keller, 2012). Porém, quando se trata de um produto de caráter alimentício, o comportamento do consumidor estuda também a relação do ser humano com os alimentos, que não está restrita somente as necessidades básicas ou biológicas, envolvem tantos outros fatores, como o convívio social, familiar, religioso, ético e psicológico, sendo capazes de moldar o comportamento de consumo de cada indivíduo (Font-I-Furnols, \& Guerrero, 2014).

As preferências dos consumidores para a carne, a partir de um ponto de vista sensorial são influenciadas pela aparência, maciez, sabor e suculência. A intenção de compra ou vontade de comprar é igualmente importante na determinação dessas preferências. (Resurreccion, 2012). Contudo, o comportamento e a percepção dos consumidores sobre a carne e produtos derivados são considerados como heterogêneos, e não se relacionam apenas com aparência e as propriedades sensoriais dos produtos, mas também com aspectos psicológicos, culturais e de marketing (Font-I-Furnols, \& Guerrero, 2014).

No estudo de Carvalho (2016), por exemplo, os consumidores das carnes de caprino e ovino se caracterizam pelo alto nível de exigência com a qualidade, uma vez que atenda a um público classe A e B, que bem informado tendem a estar sempre atento à qualidade do produto expressa no processo de produção e na embalagem, e ainda, apontou alguns fatores limitantes para a comercialização como a falta de padronização de carcaças, em razão do baixo padrão racial dos rebanhos; a irregularidade no fornecimento de carne e derivados ao mercado e o abate clandestino.

A carne ovina, apesar de ser citada como preferida por $13,8 \%$ dos entrevistados na pesquisa de Bortoli (2008), não faz parte da alimentação cotidiana dos consumidores, não competindo diretamente com a carne bovina e de frango, considerando que o preço pode ser um dos fatores limitantes do consumo. Esta evidência sugere uma inquietação, se a carne ovina é vista como saborosa pela maioria dos consumidores que a experimentam (Gonçalves et al., 2011), será que existem outros fatores que explicam o consumo da carne ovina?

Este trabalho, portanto, se justifica pela necessidade de se entender como se comporta o consumidor, quais suas preferências e principais quesitos para a escolha em consumir determinado produto, a fim de tentar atender melhor às suas exigências. Sendo assim, o presente trabalho tem o seguinte problema de pesquisa: "quais os fatores que mais influenciam o consumo da carne ovina?", e para este problema, se tem os seguintes objetivos: descobrir quais os fatores que mais influenciam o consumo da carne ovina, como objetivo geral, e analisar a diferença entre a frequência de consumo de carne ovina com os fatores que influenciam na compra da mesma.

\section{REVISÃO BIBLIOGRÁFICA Comportamento do Consumidor}

Todo o processo de compra passa antes pelo conhecimento de uma necessidade, como podem surgir de estímulos externos. Quando 
surge essa necessidade que afeta o consumidor o impulso para atender tal necessidade é denominado de motivação (Portela, 2016).

Kotler e Keller (2012) apontaram em estudos que o comportamento de compra do consumidor pode ser afetado por diferentes fatores, considerando que os fatores culturais exercem maior e mais profunda influência sobre as decisões de consumo, e ainda relatam que a reação do consumidor não é totalmente racional e cognitiva, em grande parte, existe o envolvimento emocional relacionado as marcas que pode fazer o consumidor se sentir orgulhoso ou confiante para a compra ou consumo.

O processo de decisão de compra do consumidor é composto por cinco etapas: identificação da necessidade, busca de informações, avaliação de alternativas, compra e comportamento pós-compra. Sendo que esse processo é influenciado por estímulos de marketing, características dos produtos, preço, comunicações e estratégias de distribuição, somadas aos estímulos do ambiente e ainda das características culturais, sociais pessoais e psicológicas desse comprador (Neves, \& Castro, 2011).

Em relação às decisões de compra, Davis e Clinie (2005) descrevem que os consumidores usam experiências obtidas a partir de suas decisões de consumo para atenuar incertezas externas e internas, causando assim a sua percepção produtos/mercados a evoluir de forma interativa. Para Howard e Sheth (1969), o comprador desenvolve mediadores de decisão suficientes para capacitá-lo a escolher uma marca que parece ter o melhor potencial para satisfazer seus motivos, se a marca for satisfatória, o potencial dessa marca para satisfazer seus motivos para compras posteriores é ampliado, e a probabilidade de comprar a mesma marca aumenta.

Com compras satisfatórias repetidas, de uma ou mais marcas, o comprador é susceptível de manifestar um processo de decisão de rotina de compra, em que as etapas sequenciais na compra são tão bem estruturadas que um acontecimento que desencadeia o processo também pode completá-lo. Rotina de compra implica que os mediadores de decisão são bem estabelecidos, e que o comprador tem fortes preferências pela marca (Howard, \& Sheth, 1969).
Quando o comprador está apenas começando a adquirir um produto, ele não tem experiência, nem característica que lhe permitem medir seu grau de satisfação ou insatisfação, ou seja, ele não tem um conjunto de mediadores de decisão para essa classe de produtos, e para desenvolvê-los, o consumidor procura ativamente informações através de seus ambientes comerciais e sociais. Junto com sua busca ativa de informações, o comprador pode em certa medida generalizar a partir de experiências passadas similares, realizada devido à semelhança física de uma nova classe de produto com uma classe de produtos mais antiga (Howard, \& Sheth, 2015).

A motivação intrínseca está significativamente associada com emoções negativas e positivas e proporcionando níveis desafiantes e estimulantes experiências que devem aumentar a emoção positiva e reduzir as emoções negativas (White, 2015). Cabe acrescentar, que os indivíduos são seres sociais e, segundo influências de valores, normas, tabus e crenças, suas práticas alimentares representam meios de lhes aproximar dos seus grupos de pertença ou referência; ou, ainda, de lhes distanciar socialmente (Lucchese, Batalha, \& Lambert, 2012).

Lucchese, Batalha e Lambert (2012), constataram ainda que os consumidores mais preocupados com a saúde se opõem aos que dão prioridade ao hedonismo alimentar e aos que dão valor às tradições alimentares, ou melhor, com os grupos que pensam, sobretudo, no prazer que a alimentação lhes proporciona, bem como em seu caráter cotidiano ou rotineiro, demonstrando o quão complexo e diversificado é o comportamento dos indivíduos ao se alimentarem, pois através da cada característica diferenciada de um grupo de consumidores, a tendência é que também se reinventem as formas e percepções acerca do consumo.

\section{Comportamento do Consumidor de Carne}

0 mercado mundial de carnes é de grande importância econômica em diversos países, e ao mesmo tempo é um setor complexo com uma grande diversidade quanto à forma de organização e a dinâmica de desenvolvimento, que vai desde a produção até consumo mundial de carnes, que hoje é ocupado em $70 \%$ pela carne suína e aves, a carne bovina ocupando 
$25 \%$, e o restante ocupado por outras carnes, como por exemplo, a carne ovina e caprina e de espécies exóticas (Ramos, 2006).

No Brasil, o consumo per capita de carne de aves chegou aos 42,78 kg por habitantes/ano, enquanto o consumo de carne suína per capita era de $14,6 \mathrm{~kg}$ por habitante/ano. No caso da carne de frango, em 2000, o consumo da proteína era de aproximadamente $29,91 \mathrm{~kg}$ por habitante/ano, representando em 14 anos um acréscimo de aproximadamente $143 \%$ no consumo da proteína, e no que diz respeito à carne suína, não houve grandes alterações nesse período de tempo (Abpa, 2014).

Se tratando de consumidores, alguns fatores importantes devem possuir uma redobrada atenção, especialmente no que diz respeito aos consumidores de carne, e quando se refere ao ato de comer, pois existem sentimentos complexos que são difíceis de descrever, dentre eles pode-se citar as motivações, influências, hábitos, preferências e riscos percebidos, que acabam por somar-se e misturar-se, interferindo diretamente no consumo e na preferência por determinado tipo de carne (Zamberlan et al., 2008).

Vários fatores influenciam as mudanças na demanda dos consumidores por carne, incluindo preocupações com a saúde, mudanças nas características demográficas, a necessidade de conveniência, as mudanças na distribuição e preço (Resurreccion, 2012), Barcellos (2007, p. 58) afirma que, "o consumo de carnes é permeado não apenas por aspectos fisiológicos (e ancestrais), mas também por influências culturais e psicossomáticas", o que demonstra que as mudanças culturais interferem no comportamento decisório e de compra dos consumidores.

De acordo com Verbeke e Viaene (1999), a segurança constitui a imagem mais importante da carne na dimensão de análise fatorial e até sugerem que a percepção de qualidade de carne é determinada principalmente pela sua segurança percebida.

No estudo de Bernués, Olaizola e Cocoran (2003), para amostras de consumo de carne bovina e de cordeiro, os atributos extrínsecos de carne que são mais apreciados foram alimentação animal e origem da carne, e ainda revelando que para os consumidores o armazenamento também foi considerado um atributo extrínseco importante, e considerando que o processamento/embalagem e raça dos animais foram consideradas menos importantes, demonstrando que os consumidores abordados eram muito mais preocupados com os atributos de qualidade de carne, mas consideraram que família/crianças, nutrição/saúde e segurança são itens muito importante na decisão de compra, tendência que está presente no comportamento de alguns grupos de consumidores, que buscam cada vez mais informação e qualidade, tanto de produto quanto de vida.

As atitudes dos consumidores em relação à carne podem ser divididas em dois tipos: atitudes funcionais que são estáveis e existem por longos períodos de tempo, e atitudes construtivas que são efêmeras e geralmente construídas no ponto de venda. A relevância direta das atitudes funcionais multidimensionais para a formação do aspecto mental do comportamento do consumidor e da intenção de compra de produtos cárneos baseia-se na suposição de que os consumidores aplicam perfis de atitude complexos e duradouros com múltiplas dimensões em resposta a sugestões de produtos no ponto de venda (Hamlin, 2016).

Vale destacar também a influência da educação e da renda sobre as classificações de produtos em função da origem geográfica, uma vez que foram os fatores-chave da perspectiva do mercado. 0 alto nível de educação e os altos índices de renda foram associados à preferência pela carne doméstica versus a variedade importada (Sánchez, Beriain, \& Carr, 2011).

Em geral, a presença de um rótulo de qualidade, a origem local da carne e um sistema de alimentação baseado em pastagens ou forragens verdes e não em grãos foram altamente valorizados pela maioria dos perfis de consumo. Em termos socioeconômicos, a orientação por conveniência estava mais relacionada à idade, ao local de residência e ao nível de estudos do que à renda e ao gênero (Bernués, Ripoll, \& Panea, 2012)

No estudo de Barbosa (2009), constatou-se que o fator que determina a opção pelo de carnes no município de Dom Pedrito, na grande maioria dos casos, é a tradição ou costume dos consumidores, seguido pelo sabor característico e a variedade de pratos possíveis de serem elaborados. Dentre os entrevistados $80 \%$ consomem com maior frequência carne bovina, 
15\% carne de frango e 5\% carne suína. Caso não fosse levado em consideração o preço da carne $60 \%$ dos entrevistados consumiriam carne bovina, $25 \%$ carne ovina, $10 \%$ carne de frango e $5 \%$ carne suína. 0 consumo é influenciado pela renda.

\section{O Comportamento do Consumidor de Carne Ovina}

Desde a antiguidade, as ovelhas foram domesticadas a produção de carne, embora muitas vezes, produtores prefiram a ovelha como produtora de lã, e a carne como uma atividade secundária. Soba ótica do consumidor, muita pessoas em todo o mundo consomem carne ovina, sendo que os motivos para o consumo podem estar ligado ao sabor, aspectos nutricionais e preço do produto (Ponnampalam, Holman, \& Scollan, 2016). Além destes fatores, o consume de carne ovina também é influenciado pelas crenças e atitudes das pessoas, especialmente levando em conta o cuidado com a nutrição (Traoré, Fokou, Ndour, Yougbare, Koné, Alonso, \& Bonfoh, 2018).

Alguns estudos conduzidos no Brasil trazem estimativas sobre o consumo per capita de carne ovina em cidades brasileiras. Sorio (2008) destaca que o consumo de carne ovina no país é considerável, mas ainda aquém do consumo de carne bovina. O Estado do Rio Grande do Sul é o que mais consome carne ovina, com um consumo de $2,9 \mathrm{~kg} /$ ano por habitante

Segundo Carvalho (2016), a demanda por carnes de caprinos e ovinos, em cortes padronizados, bem como por vísceras devidamente processadas, embaladas e comercializadas de forma resfriada ou congelada, vem apresentando crescimento considerável nas grandes cidades do Nordeste e do Sudeste do Brasil, principalmente nas áreas habitadas pelos segmentos populacionais detentores de maior poder aquisitivo.

0 mercado de carne é altamente competitivo, especialmente para aqueles produtos de carne com um relativamente preço mais elevado e um consumo muito limitado em comparação com outros tipos de produtos de carne, como é o caso da carne de cordeiro (Garcia, \& DeMagistris, 2013).

Em relação ao perfil dos consumidores, Ponnampalam, Holman, \& Scollan (2016) destacam que homens com maior poder aquisitivo são os que mais consomem carne ovina. Este mesmo perfil foi confirmado por Mercio (2013) em Porto Alegre/RS.

Bortoli (2008) indica que a maior parte dos consumidores de carne ovina são indivíduos do sexo masculino com poder aquisitivo acima da média, ligados a atividades rurais e com preferência de consumo concentrada nos finais de semana na forma de churrasco. 0 mesmo autor ainda destaca haver uma tendência de aumento de consumo deste tipo de carne, explicado pela probabilidade de aumento da renda e nível de instrução das pessoas (Bortoli, 2008).

No Rio Grande do Sul, Gonçalves et al. (2011), realizaram um teste de aceitação da carne de cordeiros provenientes do Alto Camaquã, com 100 consumidores durante a Expointer, Esteio - RS. Verificou-se que 92\% responderam após provar, que comprariam carne de cordeiro e, em uma escala que vai de gostei muitíssimo a desgostei muitíssimo, 48\% dos consumidores gostaram muito do produto, demonstrando que a carne ovina pode ocupar muito mais espaço no mercado consumidor do estado, desde que atenda as exigência e necessidades de seus consumidores. Em Dom Pedrito/RS, Bianchini et al. (2015 constatou que, a carne ovina é consumida por $87 \%$ dos entrevistados, ficando na segunda colocação na ordem de preferência. Os autores atribuem o fator qualidade e preço como primordiais para a compra do produto. Estas pesquisas demonstram que de fato, o povo gaúcho é um potencial consumidor de carne ovina.

\section{METODOLOGIA}

0 presente trabalho caracteriza-se como uma pesquisa descritiva quantitativa, por meio de dados primários. 0 estudo caracteriza-se por ser de natureza descritiva porque tem como principal objetivo descrever os fatores que influenciam na escolha pela carne. Para coletar os dados utilizou-se de um Survey.

A pesquisa foi realizada no município de Dom Pedrito situada na Região da Campanha no Rio Grande do Sul, onde os participantes do estudo constituíram uma amostra no qual apontaram suas opiniões e percepções sobre o consumo de carne ovina por meio de questionário estruturado. 
0 instrumento de coleta foi elaborado contendo questões relativas ao perfil do respondente e voltadas ao consumo de carne ovina; especialmente, buscando investigara carne amis consumida, as dificuldades para o consumo da carne ovina e os fatores que influenciam no consumo de carne ovina. Estes fatores foram listados com base na teoria pesquisada, apresentados na Tabela 1.

Tabela 1

Fatores que influenciam o consumo de carne ovina

\begin{tabular}{|c|c|}
\hline Características & Autor (es) \\
\hline Sabor & Ressureccion (2012). \\
\hline Cor Da Carne & Ressureccion (2012). \\
\hline Odor Característico Da Carne Ovina & Ressureccion (2012); Batista (2008). \\
\hline Qualidade Da Carne & $\begin{array}{l}\text { Batista (2008); Osório et al (2009); Bánkuti, Bánkuti, Macedo } \\
\text { (2013). }\end{array}$ \\
\hline Preço & Ressureccion (2012); Sanchez, Beriain, Carr, (2011). \\
\hline Marca Do Produto & Font-I-Furnols, Guerrero (2014); Trigueiros (2015). \\
\hline Tipo De Embalagem & Font-I-Furnols, Guerrero (2014). \\
\hline Procedência Da Carne & Verbeke, Viaene (1999); Bernués, Olaizola, Cocoran (2002). \\
\hline Tipo De Corte & Ressureccion (2012). \\
\hline Oferta Da Carne & Ressureccion (2012); Carvalho (2016). \\
\hline Gordura Da Carne & Batista (2008). \\
\hline Textura/Maciez & Ressureccion (2012). \\
\hline Preocupações Com Saúde & Ressureccion (2012). \\
\hline $\begin{array}{l}\text { Conveniência e Facilidade no } \\
\text { Preparo }\end{array}$ & Ressureccion (2012); Carvalho (2016). \\
\hline Processamento & Bernués, Olaizola, Cocoran (2002). \\
\hline Raças dos Animais & Bernués, Olaizola, Cocoran (2002); Carvalho (2016). \\
\hline Tamanho dos Cortes & Osório et al (2009). \\
\hline $\begin{array}{l}\text { Armazenamento/Congelados/In } \\
\text { Natura }\end{array}$ & Osório et al (2009). \\
\hline $\begin{array}{l}\text { Tradição No Consumo De Carne } \\
\text { Ovina }\end{array}$ & Zamberlan et al (2008). \\
\hline
\end{tabular}

Fonte: Adaptado pelos Autores (2018)

A Tabela 1 demonstra a existência de 19 fatores que influenciam o consumo da carne ovina. Estes foram mensurados por meio de uma escala Likert de 5 pontos (1: não possui nenhuma influência... 5 - possui grande influência).

Após a elaboração do instrumento de coleta de dados, o mesmo foi submetido a um préteste, realizado com os alunos do sétimo semestre do Curso Superior de Tecnologia em Agronegócio da Unipampa Campus Dom Pedrito, para que a ferramenta de pesquisa fosse testada para a eliminação de pontos de difícil compreensão, onde foram aplicados 20 questionários no dia 2 de maio de 2017 durante a aula de planejamento e processo decisório, componente curricular do $7^{\circ}$ semestre do Curso Superior de Tecnologia em Agronegócio, onde não foram grandes dificuldades de interpretação, sendo assim, a ferramenta pôde ser colocada em prática para a coleta de dados primários sem nenhum ajuste.

Após a realização do pré-teste, a coleta de dados foi realizada entre os dias 2 de maio de 2017 a 20 de maio de 2017, tanto nos pontos estratégicos de venda de carne ovina, quanto para o formulário eletrônico, que foi disponibilizado via redes sociais aos munícipes da cidade de Dom Pedrito, onde se totalizou 156 questionários, destes 142 válidos, pois os respondentes do questionário foram abordados na primeira questão por um a pergunta filtro, para aqueles que não consumem carne ovina fossem descartados desta pesquisa. Por este motivo, a amostra se caracteriza em ser de natureza não probabilística e por conveniência, visto ser conveniente entrevistar as pessoas em alguns pontos estratégicos da cidade e enviar formulários eletrônicos na rede de contato dos pesquisadores. 
E por fim, ao termino da aplicação dos questionários os dados foram tabulados em planilhas eletrônicas do software da Microsoft chamado Excel, e tratados através do software SPSS versão 22 , sendo submetidos à análise estatística descritiva, e ainda algumas variáveis foram submetidas ao Teste $\mathrm{T}$ de amostras independentes e ANOVA, utilizados para a comparação de médias dos fatores que influenciam o consumo de carne ovina e o perfil do respondente.

\section{RESULTADOS E DISCUSSÃO}

Nesta pesquisa, obteve-se 142 questionários validos e podemos caracteriza-los de acordo com a Tabela 2 .

Tabela 2

Perfil dos Respondentes que Consomem Carne Ovina



Fonte: Autores (2018)

A Tabela 2 ilustra o perfil da amostra. jovens, com grau de escolaridade elevado, sendo Observa-se uma predominância de mulheres a maioria do público, estudante e funcionários 
públicos. Esta composição de amostra justificase pelo fato de este ser o perfil da rede de contatos dos pesquisadores. Cabe ressaltar que para analisar-se uma inferência sobre o perfil que mais consume carne ovina, torna-se necessário uma comparação entre a frequência de consumo e o perfil da amostra, realizada e demonstrada na Tabela 3. Antes disto, será visualizada a frequência de consumo de carne ovina (Gráfico 1).

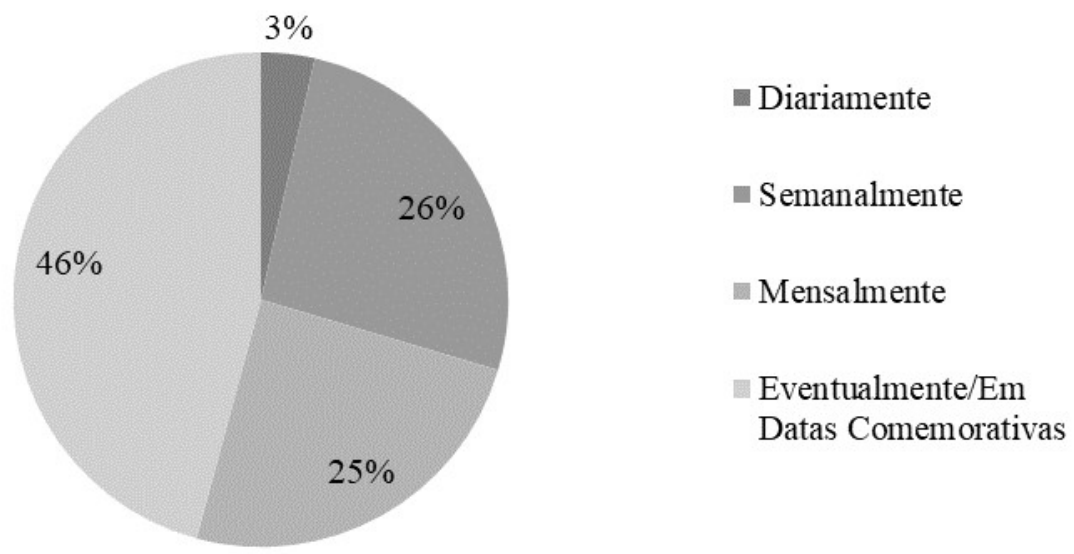

Fonte: Autores (2018)

Gráfico 1: Frequência de consumo de carne ovina

Em pesquisa sobre as atitudes do consumidor de carne, Zamberlan et al (2008) obteve como resultado para a questão sobre onde os pesquisados costumavam consumir mais carne ovina, os mesmos acreditavam que o consumo da carne de ovinos em sua maioria, se dá em datas especiais, o que podemos constatar através da análise do Gráfico 1 apresentado anteriormente, onde $46 \%$ dos respondentes costumam consumir carne ovina eventualmente e/ou em datas comemorativas.

Na sequencia, observou-se uma comparação entre a frequência de consumo e o perfil da amostra.

\section{Tabela 3}

Comparação entre a frequência de consumo e o perfil da amostra

\begin{tabular}{|c|c|c|c|c|c|c|}
\hline & Gênero & $\mathbf{N}$ & Média & $\begin{array}{l}\text { Desvio } \\
\text { Padrão }\end{array}$ & $\begin{array}{l}\text { Erro padrão } \\
\text { da média }\end{array}$ & Significância \\
\hline \multirow{3}{*}{$\begin{array}{l}\text { Frequência } \\
\text { de Consumo }\end{array}$} & Masculino & 20 & 1,71 & 0,469 & 0,125 & \multirow{2}{*}{0,423} \\
\hline & Feminino & 22 & 1,88 & 0,326 & 0,064 & \\
\hline & Idade & $\mathbf{N}$ & Média & $\begin{array}{l}\text { Desvio } \\
\text { Padrão }\end{array}$ & $\begin{array}{c}\text { Erro padrão } \\
\text { da média }\end{array}$ & Significância \\
\hline \multirow{5}{*}{$\begin{array}{l}\text { Frequência } \\
\text { de Consumo }\end{array}$} & $\begin{array}{c}\text { Menos de } \\
20 \text { anos }\end{array}$ & 3,38 & ,711 & 0,711 & 0,145 & \multirow{5}{*}{0,120} \\
\hline & $\begin{array}{c}21 \text { a } 30 \\
\text { anos }\end{array}$ & 3,20 & ,912 & 0,912 & 0,130 & \\
\hline & $\begin{array}{c}31 \text { a } 40 \\
\text { anos } \\
\end{array}$ & 3,16 & ,969 & 0,969 & 0,174 & \\
\hline & $\begin{array}{c}41 \text { a } 50 \\
\text { anos }\end{array}$ & 3,00 & ,926 & 0,926 & 0,197 & \\
\hline & $\begin{array}{c}\text { Mais de } 50 \\
\text { anos }\end{array}$ & 2,63 & 1,025 & 1,025 & 0,256 & \\
\hline
\end{tabular}




\begin{tabular}{|c|c|c|c|c|c|c|}
\hline & Instrução & $\mathbf{N}$ & Média & $\begin{array}{l}\text { Desvio } \\
\text { Padrão }\end{array}$ & $\begin{array}{l}\text { Erro padrão } \\
\text { da média }\end{array}$ & Significância \\
\hline \multirow{3}{*}{$\begin{array}{l}\text { Frequência } \\
\text { de Consumo }\end{array}$} & $\begin{array}{c}\text { Ensino } \\
\text { Médio } \\
\text { Completo } \\
\end{array}$ & 3,13 & ,942 & , 166 & 3,13 & \multirow{3}{*}{0,420} \\
\hline & $\begin{array}{c}\text { Ensino } \\
\text { Superior } \\
\text { Incompleto }\end{array}$ & 3,25 & ,816 & ,102 & 3,25 & \\
\hline & $\begin{array}{c}\text { Ensino } \\
\text { Superior } \\
\text { Completo } \\
\end{array}$ & 3,00 & 1,015 & , 174 & 3,00 & \\
\hline
\end{tabular}

Fonte: Autores (2018)

Constata-se que a frequência de consumo não depende do gênero, idade e escolaridade do respondente. Isto quer dizer que a carne ovina em tese, é apreciada por qualquer tipo de público.

Quando questionados sobre as 3 (três) principais dificuldades encontradas na hora de adquirir a carne ovina, foram apresentadas sete variáveis que, , sendo elas, pouca divulgação, pouca variedade de produtos, falta de praticidade, falta de padronização, preços elevados, ausência de produto e não percebo dificuldades, onde a variável com maior impacto e mais citado pelos respondentes foi preços elevados, seguido por ausência de produto e pouca variedade, como mostrado na Tabela 4 .

\section{Tabela 4}

Principais Dificuldades

\begin{tabular}{l|c|c}
\multicolumn{1}{c|}{ Variáveis } & Frequência (u) & Porcentagem (\%) \\
Não Percebo Dificuldades & 34 & 11,97 \\
Pouca Divulgação & 33 & 11,61 \\
Pouca Variedade & 40 & 14,08 \\
Falta de Praticidade & 11 & 3,90 \\
Falta de Padronização & 24 & 8,45 \\
Preços Elevados & 94 & 33,09 \\
Ausência de Produto & 45 & 15,84 \\
Outros $\quad 03$ & 1,06 \\
\hline \multicolumn{1}{c}{$\quad$ Total } & $\mathbf{2 8 4}$ & $\mathbf{1 0 0}$ \\
\hline
\end{tabular}

Fonte: Autores (2018)

Os consumidores pesquisados apontaram que um dos principais problemas pelos quais os consumidores acabam esbarrando no momento de consumir carne de ovinos com uma maior frequência no município é o preço, citado 94 vezes pelas pessoas consultadas, fator também constatado por Zamberlan et al. (2008), onde a carne de ovelha foi considerada pelos consumidores como a mais cara perante outras carnes no mercado, o que pode ser observado através dos resultados apresentados na Tabela 5 , aonde percebe-se que esse fenômeno também ocorre no município de Dom Pedrito, influenciando os consumidores na hora da tomada de decisão da aquisição da carne ovina.

Quando perguntados pela preferência de carnes e qual o tipo de proteína animal mais consumida por suas famílias se obteve os seguintes resultados. 
Tabela 5

Carne mais Consumida e Preferência por carnes

\begin{tabular}{l|c|c|c|c}
\multirow{2}{*}{ Variáveis } & \multicolumn{2}{c|}{ Carne Mais Consumida } & \multicolumn{2}{c}{ Carne Preferida } \\
\cline { 2 - 5 } & Frequência (u) & Porcentagem (\%) & Frequência (u) & Porcentagem (\%) \\
Carne Bovina & 98 & 69,01 & 72 & 50,70 \\
Carne de Aves & 34 & 23,94 & 20 & 14,08 \\
Carne Ovina & 09 & 6,33 & 47 & 33,09 \\
Carne Suína & 01 & 0,70 & 03 & 2,11 \\
\hline Total & $\mathbf{1 4 2}$ & $\mathbf{1 0 0}$ & $\mathbf{1 4 2}$ & $\mathbf{1 0 0}$ \\
\hline
\end{tabular}

Fonte: Autores (2018)

A carne bovina foi apontada como a mais consumida pelas famílias e a preferida pelos respondentes da pesquisa, mostrando que apesar de não ser a carne com menor valor no mercado é a que tem maior importância para os consumidores.

Ainda pode-se observar que em segundo momento a carne citada mais vezes pelos pesquisados como preferida foi a carne ovina, um dado que pode demostrar uma tendência de que o mercado de carne ovina ainda tem um grande potencial de crescimento perante $o$ mercado consumidor, e ainda uma demanda crescente, pois $33,09 \%$ da amostra dos consumidores tem a carne de ovelha como sua preferida, dados que corroboram com o estudo de Firetti et al. (2017) o que pode ser melhor observado no Gráfico 2.

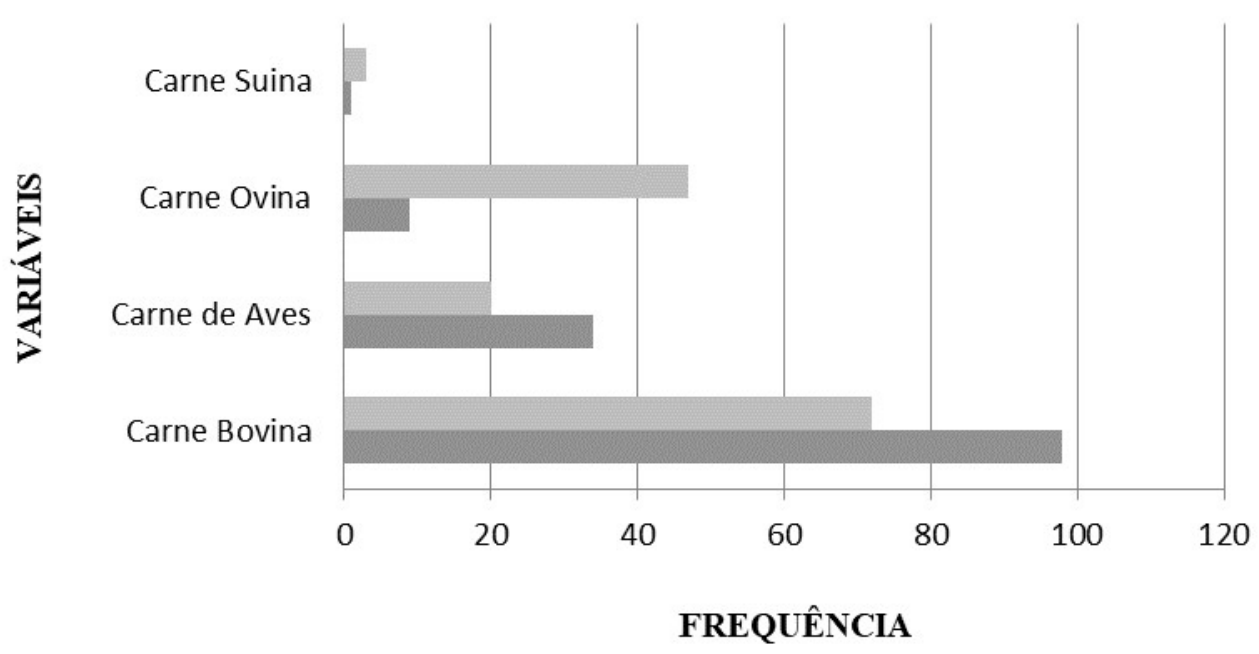

Carne Preferida

- Carne Mais Consumida

Fonte: Autores (2018)

Gráfico 2: Carne mais Consumida e Preferência por carnes

Nesta questão da ferramenta de coleta de dados utilizada para essa pesquisa, solicitou-se aos respondentes que classificassem 19 variáveis de acordo com a relevância no consumo de carne ovina, sendo um (1) "não possui nenhuma relevância", e cinco (5) "possui grande relevância", que resultou nos dados apresentados na Tabela 6 . 
Tabela 6

Resultados da análise do grupo que consume de carne ovina

\begin{tabular}{|c|c|c|c|}
\hline & Variáveis & Médias & Desvio Padrão \\
\hline V1 & Sabor & 4,37 & 1,14 \\
\hline V2 & Cor da carne & 3,59 & 1,40 \\
\hline V3 & Odor Característico da carne ovina & 3,45 & 1,43 \\
\hline V4 & Qualidade da Carne & 4,34 & 1,14 \\
\hline V5 & Preço & 3,57 & 1,54 \\
\hline V6 & Marca do produto & 2,82 & 1,44 \\
\hline V7 & Tipo de embalagem & 2,85 & 1,51 \\
\hline V8 & Procedência da carne & 4,08 & 1,31 \\
\hline V9 & Tipo de corte & 3,54 & 1,41 \\
\hline V10 & Oferta da carne no município & 3,49 & 1,48 \\
\hline V11 & Gordura da carne & 3,50 & 1,23 \\
\hline V12 & Textura/Maciez & 4,13 & 1,24 \\
\hline V13 & Preocupações com saúde & 3,65 & 1,48 \\
\hline V14 & Conveniência e facilidade no preparo & 3,48 & 1,48 \\
\hline V15 & Processamento & 3,30 & 1,44 \\
\hline V16 & Raças dos animais & 2,89 & 1,48 \\
\hline V17 & Tamanho dos cortes & 3,18 & 1,49 \\
\hline V18 & Armazenamento/Congelados/In natura & 3,40 & 1,50 \\
\hline V19 & Tradição no consumo de carne ovina & 3,62 & 1,44 \\
\hline
\end{tabular}

Fonte: Autores (2018)

Os itens que apresentaram maiores médias foram "sabor", "qualidade da carne", "textura e maciez". Estes resultados apoiam as pesquisas de Ressureccion (2012), ao destacar a importância do sabor dos alimentos e da textura, Batista (2008), Osório et al. (2009), Bánkuti, Bánkuti e Macedo (2013), enfatizando a qualidade da carne como característica importante percebida pelos consumidores. Os achados também vão ao encontro das evidências de Gonçalves et al. (2011), ao destacarem que grande parte das pessoas que provam a carne ovina, gostam do produto. Possivelmente, este gosto contribui para uma nova compra,

Percebe-se, que os aspectos inerentes a qualidade do produto são os mais determinantes para o consumo da carne ovina. Talvez isto ocorra porque de fato, consumidores usam experiências obtidas a partir de suas decisões de consumo para atenuar incertezas externas e internas (Davis, \& Clinie, 2005), neste caso, a percepção de qualidade do produto acaba sendo a decisão de compra abrangendo o sabor, a textura/maciez e o julgamento sobre a qualidade da carne. No decorrer da análise dos dados, se pensou que haveriam diferentes percepções entre os consumidores de carne ovina que participaram da pesquisa de acordo com a frequência de consumo, e a partir disso, foi aplicado às variáveis o Teste $T$ de amostras independentes para que se pudesse verificar qual a variável que possuía mais relevância para os respondentes que possuíam maior frequência no consumo de carne ovina, ou seja, diariamente e/ou semanalmente, em comparação com pessoas que consomem eventualmente ou mensalmente.

Tabela 7

Resultados do Teste T

\begin{tabular}{l|c|c|c|c}
\multirow{2}{*}{\begin{tabular}{c}
\multirow{2}{*}{ Itens } \\
\multirow{2}{*}{ Sabor }
\end{tabular}} & Frequência de Consumo & Média & $\begin{array}{c}\text { Desvio } \\
\text { Padrão }\end{array}$ & Significância \\
\cline { 1 - 4 } & Diariamente/Semanalmente & 4,3095 & 1,27811 & \multirow{2}{*}{0,668} \\
\cline { 2 - 4 } Cor & Mensalmente/Eventualmente & 4,4000 & 1,08246 & 0,359 \\
\hline
\end{tabular}




\begin{tabular}{|c|c|c|c|c|}
\hline & Mensalmente/Eventualmente & 3,5500 & 1,35866 & \multirow{3}{*}{0,897} \\
\hline \multirow[b]{2}{*}{ Odor } & Diariamente/Semanalmente & 3,4762 & 1,53397 & \\
\hline & Mensalmente/Eventualmente & 3,5100 & 1,35955 & \\
\hline \multirow{2}{*}{ Qualidade da Carne } & Diariamente/Semanalmente & 4,3095 & 1,15796 & \multirow{2}{*}{0,885} \\
\hline & Mensalmente/Eventualmente & 4,3400 & 1,13902 & \\
\hline \multirow[b]{2}{*}{ Preço } & Diariamente/Semanalmente & 3,2381 & 1,55876 & \multirow{2}{*}{0,096} \\
\hline & Mensalmente/Eventualmente & 3,7100 & 1,51954 & \\
\hline \multirow{2}{*}{ Marca do produto } & Diariamente/Semanalmente & 2,7143 & 1,50261 & \multirow{2}{*}{0,463} \\
\hline & Mensalmente/Eventualmente & 2,9100 & 1,42201 & \\
\hline \multirow{2}{*}{ Tipo de embalagem } & Diariamente/Semanalmente & 2,7619 & 1,62014 & \multirow{2}{*}{0,548} \\
\hline & Mensalmente/Eventualmente & 2,9300 & 1,47199 & \\
\hline \multirow{2}{*}{ Procedência da carne } & Diariamente/Semanalmente & 4,0238 & 1,40536 & \multirow{2}{*}{0,884} \\
\hline & Mensalmente/Eventualmente & 4,0600 & 1,31671 & \\
\hline \multirow{2}{*}{ Tipo de corte } & Diariamente/Semanalmente & 3,5476 & 1,40039 & \multirow{2}{*}{0,901} \\
\hline & Mensalmente/Eventualmente & 3,5800 & 1,40834 & \\
\hline \multirow{2}{*}{ Oferta da carne no município } & Diariamente/Semanalmente & 3,3333 & 1,55652 & \multirow{2}{*}{0,407} \\
\hline & Mensalmente/Eventualmente & 3,5600 & 1,45171 & \\
\hline \multirow[b]{2}{*}{ Gordura da carne } & Diariamente/Semanalmente & 3,5238 & 1,25403 & \multirow{2}{*}{0,981} \\
\hline & Mensalmente/Eventualmente & 3,5000 & 1,22680 & \\
\hline \multirow{2}{*}{ Textura/Maciez } & Diariamente/Semanalmente & 4,2381 & 1,14358 & \multirow{2}{*}{0,549} \\
\hline & Mensalmente/Eventualmente & 4,1000 & 1,29099 & \\
\hline \multirow{2}{*}{ Preocupações com saúde } & Diariamente/Semanalmente & 3,9048 & 1,49486 & \multirow{2}{*}{0,247} \\
\hline & Mensalmente/Eventualmente & 3,5900 & 1,46401 & \\
\hline \multirow{2}{*}{$\begin{array}{l}\text { Conveniência e facilidade no } \\
\text { preparo }\end{array}$} & Diariamente/Semanalmente & 3,5714 & 1,51646 & \multirow{2}{*}{0,654} \\
\hline & Mensalmente/Eventualmente & 3,4500 & 1,45210 & \\
\hline \multirow{2}{*}{ Processamento } & Diariamente/Semanalmente & 3,3571 & 1,51128 & \multirow{2}{*}{0,890} \\
\hline & Mensalmente/Eventualmente & 3,3200 & 1,42758 & \\
\hline \multirow{2}{*}{ Raças dos animais } & Diariamente/Semanalmente & 3,3095 & 1,48961 & \multirow{2}{*}{$0,036^{*}$} \\
\hline & Mensalmente/Eventualmente & 2,7400 & 1,44684 & \\
\hline \multirow{2}{*}{ Tamanho dos cortes } & Diariamente/Semanalmente & 3,1429 & 1,52334 & 0807 \\
\hline & Mensalmente/Eventualmente & 3,2100 & 1,47911 & 0,807 \\
\hline Armazenamento/Congelados/In & Diariamente/Semanalmente & 3,2381 & 1,55876 & \\
\hline & Mensalmente/Eventualmente & 3,4700 & 1,48021 & 0,403 \\
\hline Tradição no consumo de carne & Diariamente/Semanalmente & 3,8333 & 1,41278 & \\
\hline ovina & Mensalmente/Eventualmente & 3,5500 & 1,46594 & $0, \angle 90$ \\
\hline
\end{tabular}

Fonte: Autores (2018). Nota. ${ }^{*}$ Significante a 0,05

Após a realização do Teste T, verificou-se que somente a "raça dos animais" obteve diferença estatística em relação à periodicidade de consumo da carne ovina. Neste caso, consumidores que consomem carne ovina com maior periodicidade dão mais importância à raça dos animais. Este resultado faz sentido, visto que em tese, um maior consumo repetido faz com que as pessoas fiquem mais experts sobre o produto, e até mesmo, mais exigentes.

\section{CONSIDERAÇÕES FINAIS}

Este trabalho teve como foco principal descobrir quais os fatores que mais influenciam o consumo da carne ovina e analisar a diferença entre a frequência de consumo de carne ovina com os fatores que influenciam na compra da mesma.

Os dados analisados apontam que para a amostra de consumidores que respondeu a pesquisa, os itens mais relevantes para o consumo de carne ovina foram "sabor", "qualidade da carne", "textura e maciez". Os resultados indicam que os consumidores dão mais importância aos aspectos que dizem respeito à qualidade da carne ovina. Os itens menos considerados foram tipo de embalagem e marca do produto. Sobre as variáveis pesquisadas, a raças dos animais foi à única que obteve diferença estatística entre a frequência de consumo. Neste caso, consumidores que consomem carne ovina com maior periodicidade dão mais importância à raça dos animais. Isto indica que pessoas que consomem 
mais um produto tende a ser tornar experts, e possivelmente, mais exigentes.

A partir desse estudo, pode-se chegar a algumas conclusões importantes para futuras intervenções na cadeia da ovinocultura no município, porém como outro estudo qualquer, o mesmo possui limitações o que restringe a uma análise de uma pequena parcela do município, e que não deve servir como alicerce para o município inteiro, pois os dados aqui levantados são específicos de um grupo de respondentes, porém pode ser ainda ampliado para que em futuras pesquisas tenha uma abrangência maior contemplando não somente o município de Dom Pedrito, mas também a região como um todo, buscando o entendimento e o fortalecimento do mercado da ovinocultura.

Por fim, estudos como este, que visem o comportamento do consumidor, suas percepções e exigências, são extremamente importantes para a cadeia produtiva, pois através destas informações pode-se melhorar a qualidade dos produtos que chegam até o mercado, fazendo com que a demanda e as exigências dos consumidores sejam atendidas, gerando um fortalecimento do mercado da ovinocultura.

\section{REFERÊNCIAS}

ABPA - Associação Brasileira de Proteína Anima (2016). Disponível em <www.abpabr.com.br> Acesso em: 10 de novembro de 2016.

Bánkuti, F. I., Bánkuti, S. M. S., \& Macedo, F. A. (2013). A informalidade em sistemas agroindustriais: um estudo exploratório dos hábitos de consumo de carne ovina na cidade de Maringá, Estado do Paraná. Informações Econômicas, 43(1), 5-17.

Barbosa, M. R., Costa, P. T., Senna, A. J. T., Ferreira, F. R., \& Bittencourt, R. F. (2009). Caracterização Do Consumo De Carnes No Municĺpio De Dom Pedrito-rs. Anais do Salão Internacional de Ensino, Pesquisa e Extensão, 1(1).

Barcellos, M. D. D., Lans, I. A., \& Thompson, J. (2007). "Beef lovers": um estudo cross-cultural sobre o comportamento de consumo de carne bovina (Tese de Doutorado). Universidade Federal do Rio Grande do Sul.

Batista, A. (2008). Qualidade de carne de ovinos Morada Nova, Santa Inês e Mestiços Dorper $x$ Santa Inês submetidos a dietas com diferentes concentrações energéticas. (Tese de Doutorado). Universidade Federal da Paraíba.

Bernués, A., Olaizola, A., \& Corcoran, K. (2003). Labelling information demanded by European consumers and relationships with purchasing motives, quality and safety of meat. Meat science, 65(3), 1095-1106.

Bernués, A., Olaizola, A., \& Corcoran, K. (2003). Extrinsic attributes of red meat as indicators of quality in Europe: an application for market segmentation. Food quality and preference, 14(4), 265-276.

Bernués, A., Ripoll, G., \& Panea, B. (2012). Consumer segmentation based on convenience orientation and attitudes towards quality attributes of lamb meat. Food Quality and Preference, 26(2), 211-220.

Bianchini, B. D. (2015). Caracterização do consumidor da carne ovina da cidade de Dom Pedrito-RS. Anais do Salão Internacional de Ensino, Pesquisa e Extensão, 7(2).

Canozzi, M. E. A., Barcellos, J. O. J., Scharnberg, F., Brandão, M. D. D., Bortoli, E. C., Reis, D., ... \& Machado, J. A. D. (2013). Caracterização da cadeia produtiva de carne ovina no Rio Grande do Sul, Brasil. Pesq Agrop Gaúcha, 19, 130-139.

Carvalho, R. B. (2016). Potencialidades dos mercados para os produtos derivados de caprinos e ovinos.

Costa, R. G., da Silva, N. V., de Medeiros, G. R., \& Batista, A. S. M. (2011). Características sensoriais da carne ovina: sabor e aroma. Revista Científica de Produção Animal, 11(2).

Davies, A., \& Cline, T. W. (2005). A consumer behavior approach to modeling monopolistic competition. Journal of Economic Psychology, 26(6), 797-826.

De Bortoli, E. D. C. (2008). O mercado de carne ovina no Rio Grande do Sul sob a ótica de diversos agentes. (Dissertação de Mestrado). Universidade Federal do Rio Grande do Sul.

FAO - Organização das Nações Unidas para a Agricultura e Alimentação (2007). Estatísticas FAO. Disponível em: <http://data.fao.org/measure?entryld=http:/ /data.fa o.org/ref/7fab5e02-f65d-464a-8a47a674a7bb4d50 >. Acesso em 02 de junho 2017.

Firetti, R., Alberti, A. L. L., Zundt, M., Carvalho-Filho, A. A. D., \& Oliveira, E. C. D. (2017). Identificação de Demanda e Preferências no Consumo de Carne Ovina com Apoio de Técnicas de Estatística Multivariada. Revista de Economia e Sociologia Rural, 55(4), 679692.

Font-i-Furnols, M., \& Guerrero, L. (2014). Consumer preference, behavior and perception about 
meat and meat products: An overview. Meat science, 98(3), 361-371.

Gracia, A., \& de-Magistris, T. (2013). Preferences for lamb meat: A choice experiment for Spanish consumers. Meat science, 95(2), 396-402.

Gonçalves, M.S. et al. (2011). Acceptance of sheep and goat meat from Alto Camaquã. Revista Argentina de Producción Animal, 1, 113-113.

Guerreiro, J., Rita, P., \& Trigueiros, D. (2015). Attention, emotions and cause-related marketing effectiveness. European Journal of Marketing, 49(11/12), 1728-1750.

Hamlin, R. (2016). Functional or constructive attitudes: Which type drives consumers' evaluation of meat products? Meat science, 117, 97-107.

Howard, J. A., \& Sheth, J. N. (1969). The theory of buyer behavior. New York, 63.

Kotler, P., \& Keller, K. L. (2012). Administração de Marketing. São Paulo: Pearson.

Lopes, M. A., Maia, É. M., Bruhn, F. R. P., Custódio, I. A., da Rocha, C. M. B. M., \& Faria, P. B. (2017). Fatores associados à percepção e atitude de consumidores de carne bovina com certificação de origem em Uberlândia, Minas Gerais. Ceres, 64(1).

Lucchese-Cheung, T., Batalha, M. O., \& Lambert, J. L. (2012). Comportamentos do consumidor de alimentos: tipologia e representação da comida. Agroalimentaria, 18(35).

Mattar, F. (2011). Pesquisa de Marketing: Metodologia e Planejamento. 6ed. São Paulo: Atlas.

Mercio, T. Z. (2013). O comportamento do consumidor de carne ovina e sua percepção de qualidade por meio de pistas e atributos (Dissertação de Mestrado). Universidade Federal do Rio Grande do Sul.

Neves, M.; Castro, L. (2011). Marketing e estratégia em agronegócios e alimentos. 1ed. São Paulo: Atlas.

Nocchi, E. (2001). Os efeitos da crise da lã no mercado internacional e os impactos sócio-econômicos no município de Santana do Livramento-RSBrasil (Dissertação de Mestrado). Universidad Nacional de Rosario, Rosario, Argentina).

Osório, J. C. D. S., Osório, M. T. M., \& Sañudo, C. (2009). Características sensoriais da carne ovina. Revista Brasileira de Zootecnia, 38, 292300.

Paiva, S. R., Silvério, V. C., Paiva, D. D. F., McManus, C., Egito, A. A., Mariante, A. D. S., ... \& Dergam, J. A. (2005). Origin of the main locally adapted sheep breeds of Brazil: a RFLP-PCR molecular analysis. Archivos de Zootecnia, 54(206-207), 395-399.
Ponnampalam,E. N., Holman, B. W. B, \& Scollan, N. D. (2016). Sheep: Meat. Encyclopedia of Food and Health, 750-757.

Portela, C. (2016). O Marketing e o Comportamento do Consumidor. PUC - MBA em Marketing, São Paulo.

Ramos Filho, F. S. V. (2006). Qualidade na cadeia da carne bovina: o caso da carne orgânica (Dissertação de Mestrado). Universidade Federal Rural do Rio de Janeiro.

Resurreccion, A. V. A. (2004). Sensory aspects of consumer choices for meat and meat products. Meat Science, 66(1), 11-20.

Reys, M. A., Silveira, V. C. P., Viana, J. G. A., de Castro Gabriel, C., \& Barchet, I. (2010). Atributos de Importância na Compra de Carne Ovina pelos Consumidores de Santa Maria, RS. Revista em Agronegócio e Meio Ambiente, 3(2), 201-210.

Saab, M. S. B., Neves, M. F., \& Cláudio, L. D. G. (2009). O desafio da coordenação e seus impactos sobre a competitividade de cadeias e sistemas agroindustriais. Revista Brasileira de Zootecnia, 412-422.

Sánchez, M., Beriain, M. J., \& Carr, T. R. (2012). Socioeconomic factors affecting consumer behaviour for United States and Spanish beef under different information scenarios. Food Quality and Preference, 24(1), 30-39.

Sorio, A. (2008). Consumo Brasileiro de Carne Ovina: Como foi em 2007? Revista o Berro, 110, Abril de 2008.

Sorio, A., \& Rasi, L. (2010). Ovinocultura e abate clandestino: um problema fiscal ou uma solução de mercado? Revista de Política Agrícola, 19(1), 71-83.

Traoré, S. G., Fokou, G., Ndour, A. P. N., Yougbare, B., Koné, P., Alonso, S., ... \& Bonfoh, B. (2018). Assessing knowledge, beliefs and practices related to the consumption of sheep and goat meat in Senegal. Global food security, 19, 6470.

Trigueiros, J. G. P. R. D. (2015). Attention, emotions and cause related marketing effectiveness. European Journal of Marketing, 49, p. 17281750.

Verbeke, Wim; Viaene, Jacques. (1999). Beliefs, attitude and behaviour towards fresh meat consumption in Belgium: empirical evidence from a consumer survey. Food quality and preference, $10(6), 437-445$.

Viana, J. G. A. (2008). Panorama geral da ovinocultura no mundo e no Brasil. Revista Ovinos, 4(12), 44-47.

Viana, J. G. A., \& Silveira, V. C. P. (2009). Cadeia produtiva da ovinocultura no Rio Grande do Sul: um estudo descritivo. Revista em Agronegócio e Meio Ambiente, 2(1), 9-20. 
White, C. (2015). The impact of motivation on customer satisfaction formation: a selfdetermination perspective. European Journal of Marketing, 49(11/12), 1923-1940.

Zamberlan, L., Sparemberger, A., Büttenbender, P. L., Wagner, A., \& Zamin, M. (2008). As atitudes do consumidor de carne: um estudo exploratório das percepções e o papel da cultura no consumo. XXXII Encontro da ANPAD, Rio de Janeiro/RJ.

\title{
Factors Influencing Sheep Meat Consumption
}

\begin{abstract}
The present research aimed to analyze which variables are most relevant for sheep meat consumers in the municipality of Dom Pedrito RS, with the objective of analyzing their perceptions, verifying which factors are most relevant for meat consumption, and which relation to the frequency of consumption. The methodology used was the application of a survey questionnaire, to collect primary data at strategic points of sale of sheep meat, and analysis through descriptive statistics. We obtained as a result, intrinsic attributes such as flavor, texture and softness, and extrinsic attributes such as price. In addition, price was the variable responsible for guiding consumption frequency. Finally, studies aimed at the consumer market are of fundamental importance for the production chain, because through the perceptions of consumers, a product can be offered that meet the needs and demand of consumers.
\end{abstract}

Keywords: Consumer Behavio, Market, Sheep Meat, Consumption, Sheep Farming. 